\title{
Introduction to the Special Issue of the Journal of Agricultural and Environmental Ethics on Ethical Aspects of Large-Scale Land Acquisition in Developing Countries
}

\author{
Lieske Voget-Kleschin • Konrad Ott
}

Accepted: 6 February 2013

(C) Springer Science+Business Media Dordrecht 2013

The phenomenon of Large-scale Land Acquisitions (LaSLA) in developing countries encompasses public and private investment in land (both purchase and long-term lease) in Africa, Central and South East Asia and Latin America. Whether this phenomenon represents much-needed investment or foreign "land grab" remains a matter of dispute: Proponents claim that-given certain conditionsLaSLA can result in capital influx, infrastructure investment, technology transfer, and job creation. They therefore understand LaSLA as a win-win-situation, allowing the exploitation of "underutilized" agricultural potential, thereby contributing to an essential increase in global agricultural commodity production and simultaneously producing much-needed rural development in developing countries. Contrariwise, opponents argue that land targeted by LaSLA is neither unused nor underutilized. They therefore expect LaSLA to result in detrimental effects for local communities, especially loss of livelihood. Furthermore, they fear negative environmental effects such as biodiversity loss, soil erosion, and increased greenhouse gas emissions.

The special issue at hand aims at investigating LaSLA from an ethical perspective. As such, it is based on a broad understanding of applied ethics. First, we conceive of applied ethics as targeted at but also anchored in real world cases. This is why we understand case studies that make the moral aspects of LaSLA explicit as constituting an indispensible part of ethical analysis. Accordingly, the special issue encompasses four case studies, namely the case of Limphasa Sugar Corporation in Malawi, financed by a Malawian and some British Investors (Blessings et al.), Chinese-based land-acquisitions in Cambodia (Neef et al.), a Norwegian land appropriation in Ghana aiming at biofuel production (Wisborg) and

\footnotetext{
L. Voget-Kleschin $(\bowtie) \cdot$ K. Ott

Department of Philosophy, Kiel University, Leibnizstr. 4, 24118 Kiel, Germany

e-mail: voget-kleschin@philsem.uni-kiel.de

K. Ott

e-mail: ott@philsem.uni-kiel.de
} 
three projects in Tanzania, encompassing two afforestation projects under the Kyoto Clean Development Mechanism (CDM), and one project aiming at bioenergy production (Purdon). These case studies back the underlying thesis of this issue, namely that LaSLA constitutes a moral problem that asks for ethical analysis and reflection. In terms of such ethical reflection, this issue spans a broad range of issues, among them sustainability issues (Purdon, Voget-Kleschin, Voget-Kleschin, and Stephan), human rights (Toft, Voget-Kleschin and Stephan, Wisborg), and an analysis from a Rawlsian framework of thought (Montilla and Schwarze). Finally, engaging in a thorough analysis of LaSLA necessitates acknowledging issues of power, corruption, and policy. While these aspects feature to some degree in all of the papers, they are especially prominent in Neef et al.'s and Wisborg's paper, which address discursive tactics of depoliticizing struggle against and legitimizing new allocation of land.

The first two papers offer case studies from a political-economy perspective. The paper by Blessings Chinsinga, Michael Chasukwa and Sane Pashane Zuka, is titled The Political Economy of Land Grabs in Malawi: Investigating the Contribution of Limphasa Sugar Corporation in Bringing Rural Development. It focuses on a case study from rural Malawi. The authors discuss land availability in the region, lay out the legal framework, introduce the main actors and their motives, and give a comprehensive account of the land acquisition process. Regarding those people for whom the land acquisition process resulted in loss of (access to) land, they argue that compensation has taken place, but not all people got compensated. Some did not get compensated for loss of land but only for improvements made on the land. Part of the compensation did not reach the concerned smallholders due to elite grabbing. Furthermore, Blessings et al. demonstrate that the project encroaches on food security for local people and poses environmental risks by draining one of the districts's major wetland areas. In regard to expected benefits of the project, the authors argue that while national benefits such as increase in tax base and foreign exchange earnings do occur, benefits to local communities, especially the creation of jobs with a decent income could not be observed. The authors conclude that in Malawi, LaSLA does not exhibit potential to achieve sustainable and transformative rural development.

The second paper focuses on The Politics and Ethics of Land Concessions in Rural Cambodia. Andreas Neef, Siphat Touch and Jamaree Chiengthong present a case study from Cambodia investigating two types of governmental land concessions. In doing so, they focus on the mechanism of land allocation and the discourse surrounding land concessions. They demonstrate first, that and how the allocation of "economic land concessions" results in displacement and loss of livelihood for local people. Second, they argue that the Cambodian ruling elite deliberately employs so called "social land concessions" to smooth the adverse social impacts of economic land concessions and thus minimize resistance. Third, they show that these social land concessions in fact formalize displacement and distributional injustice. Finally, they argue that the Cambodian ruling elite exploits international aid agencies in terms of co-financing such social land-concessions.

In summary, both case studies paint a rather pessimistic picture of LaSLA, presenting the phenomenon as tilting rather towards "landgrab" instead of 
"development opportunity." They thus account for conceiving of LaSLA as problematic and necessitating ethical analysis.

The subsequent three papers are each based on a distinct conception of sustainability. The paper Large-scale land acquisition: evaluating its environmental aspects against the background of strong sustainability by Lieske Voget-Kleschin conceptualizes sustainable development as a normative concept based on claims for intra- and intergenerational justice. In this framework, she outlines an argument in favor of strong sustainability based on which she develops guidelines for the sustainable use of natural capital. These guidelines are employed to reason sustainability criteria in regard to LaSLA's environmental consequences. The guidelines and criteria focus on LaSLA's environmental dimension and do not target social consequences. Accordingly, the author argues that complying with them constitutes a necessary though not sufficient condition for LaSLA to qualify as not violating claims for sustainability.

In contrast to Voget-Kleschin's focus on strong sustainability, Mark Purdon's paper, Land Acquisitions in Tanzania: strong sustainability, weak sustainability and the importance of comparative methods focuses on a comparative evaluation of two LaSLA-projects from both a strong and weak sustainability perspective. He conceives of sustainability as non-declining utility over time, weak sustainability as allowing for and strong sustainability as rejecting substitutability between critical natural and man-made capital. Under the heading of strong sustainability, Purdon discusses the productivity of the land acquired as well as the environmental effects of land acquisition. He shows that the CDM projects targeted unproductive land and did not lead to negative environmental effects that qualify as deterioration of critical natural capital. By contrast, in regard to the biofuel project interviewees claimed that land acquired had formerly been used for farming. Furthermore, this project features negative impacts on water availability in the region. Under the heading of weak sustainability, Purdon tackles employment, social services, and compensation of local people for loss of (access to) land. In regard to employment and social services, he argues that while the CDM-projects created employment benefits, the biofuel project generated few benefits. In regard to compensation he shows that in both the CDM- and the biofuel-projects compensation was provided to only a limited number of individuals who had made permanent investments in land such as farms, tree planting or clay pits. Based on this investigation, Purdon concludes that the CDM projects meet the conditions of both strong and weak sustainability. By contrast, he argues that the biofuel project neither meets conditions of strong sustainability on account of its negative effects on water availability, nor conditions of weak sustainability on account of its lack of positive social effects. A further key finding of Purdon's analysis is that in regard to his case studies in Tanzania and at the time of fieldwork in 2009, land acquisitions did not impact food security. Purdon's paper stands out in so far as it is the only paper in this issue that takes the view that under some conditions LaSLA was able to deliver significant economic benefits. In contrast to the other papers, he thus takes a comparatively positive stance towards LaSLA.

The paper The potential of standards and codes of conduct in governing largescale land acquisition in developing countries towards sustainability by Lieske 
Voget-Kleschin and Setareh Stephan is linked to the paper by Voget-Kleschin as it draws on the same basic understanding of sustainability as a normative concept based on claims for intra- and intergenerational justice. The authors demonstrate that this understanding allows conceiving of LaSLA's negative social effects on the population in host countries as direct violations of justice and of its adverse environmental consequences as mishandling natural capital and consequently as indirect violation of justice. Voget-Kleschin and Stephan specify these claims by drawing on a human rights approach and the sustainability guidelines of efficiency, consistency, and resilience respectively to arrive at sustainability criteria regarding LaSLA's social and environmental consequences. Subsequently, these sustainability criteria are compared to existing proposals regarding sustainability standards for LaSLA as well as to the further developed sustainability standards for biofuels. The authors show that and in how far their conceptually inferred criteria are broader than existing standards. Furthermore, the authors observe that existing proposals regarding standards for LaSLA mainly focus on social criteria, and neglect environmental aspects. By contrast, existing standards for bioenergy primarily address environmental aspects. Voget-Kleschin and Stephan conclude that an encompassing standard for LaSLA should integrate both dimensions. The paper closes with a discussion of the implications of experiences from the development and implementation of sustainability standards for biofuels for the prospects and options regarding corresponding standards for LaSLA. In this regard, the authors highlight the increasing number and heterogeneity of standards that result in difficulty to harmonize and ultimately apply such standards. This is why the authors conclude by recommending a (temporary) moratorium of LaSLA that links the acceptability of projects to conclusive proposals for addressing these issues.

The discussion of existing standards leads over to the last three papers of this issue. These papers critically address different approaches targeted at avoiding or leastwise mediating LaSLA's problematic social and environmental consequences. Are land deals unethical? The ethics of large-scale land acquisitions in developing countries by Kristian Høyer Toft lays out the contours of three governance approaches for dealing with LaSLA: the liberal code of conduct proposed by the World Bank, the critical human rights approach of the UN special rapporteur on the right to food, Olivier De Schutter, and the anti-liberal, Marxist-inspired land sovereignty approach of Borras and Franco. Subsequently, Toft addresses three ethical issues raised by his argument: First, he discusses an aspect prominently featuring in the land sovereignty approach, namely, a human right to land. He then goes on to address issues of adequate inclusion. Though acknowledging the urgent need of inclusion of local people in concrete decision making about land deals, the author focuses on inclusion in the process of developing standards for regulating LaSLA and inclusion of marginalized voices in ethical methods, namely Habermasian discourse ethics and Rawlsian reflective equilibrium. Toft closes by arguing that citizens who participate in a global structure that facilitates and promotes land grabbing also become responsible for such landgrabbing, due to their upholding these very same institutions.

Toft distinguishes between what he calls liberal codes of conduct and a human rights approach. He assigns the Voluntary Guidelines on the Responsible 
Governance of Tenure of Land, Fisheries and Forests in the Context of National Food Security to the realm of codes of conducts on account of their voluntariness. For him, the human rights perspective as proposed by de Schutter differs from this in that it aims at ensuring accountability. By contrast, Poul Wisborg acknowledges that de Schutter contributed substantially to linking land acquisition and human rights but argues that the voluntary guidelines constitute one of the major policy initiatives taking a human rights perspective. In his paper, Human rights against land grabbing? A reflection on norms, policies and power, Wisborg challenges the idea of a human right to land and instead proposes focusing on the interface of land and existing human rights, specifically those addressing issues of governance, fair process, just outcomes, and development. By doing so, he develops a human rights approach applicable to transnational land acquisitions. Subsequently, the author employs this framework in first evaluating the Voluntary Guidelines as the major global policy effort to promote a human rights approach to land and second, in discussing a Norwegian land appropriation in Ghana. Wisborg concludes that on a conceptual level, a human rights approach is comprehensive, nuanced, contextual, and precautionary and thus argues for employing such a normative approach in qualifying ethically unacceptable land acquisition or land grabbing. However, on the practical level, Wisborg questions whether human rights approaches, even with the impetus of the Voluntary Guidelines, can re-shape power relations and practice and can thus escape critique that global guidelines de-politicize land grabbing and defuse action for social justice through alternatives to land alienation.

The paper John Rawls's Theory of Justice and Large-Scale Land Acquisitions. A Law and Economics Analysis of Institutional Background Justice in Sub-Saharan Africa by Luis Tomás Montilla Fernández and Johannes Schwarze draws on Rawls's Theory of justice and asks if and how LaSLA affects the background institutions for distributive justice. To this end, the authors relate Rawls's general claims regarding these background institutions to the phenomenon of LaSLA and contrast the resulting claims with empirical insights gained from an analysis of 81 LaSLA-contracts in Sub Saharan Africa. On this basis, the authors diagnose that background institutions that would be necessary for LaSLA to achieve fair outcomes are lacking. Furthermore, they do not find evidence that LaSLA does in any way contribute to an improvement of these background institutions. The paper closes with a discussion of the possible role of international law in improving the current situation surrounding LASLA. It concludes that under the actual judicial circumstances the possibilities of correcting this situation by applying international law are limited.

This special issue primarily aims at contributing to a deeper understanding of the ethical aspects involved in LaSLA. However, we perceive ethical reflection as always geared towards action guidance. Accordingly, in so far as understanding the descriptive and normative ingredients of a challenge constitutes a necessarythough not sufficient - step in tackling this challenge, we hope that this special issue may also contribute to an ethically adequate political handling of LaSLA.

The special issue results from an interdisciplinary research project on "Largescale land acquisition and sustainable development" (www.lasla.org) in collaboration with the Journal of Agricultural and Environmental Ethics. The editors would 
like to thank Richard Haynes from JAGE for the good cooperation. Furthermore, we gratefully acknowledge financial support of the German Federal Ministry of Education and Research (BMBF) in the course of the research project. 